Background Attachment refers to an infant's instinct to seek close proximity to their caregiver and research has shown it is important in promoting a child's healthy social and emotional development. Parenting interventions have been developed in order to promote secure attachment and reduce disorganised attachment. Many interventions used in routine practice have a limited evidence base (e.g. no randomised controlled trials [RCTs]) and it is important that they are robustly evaluated to ensure they are safe and effective.

Objectives The research aimed to; conduct a large scale survey to determine what interventions are being used in UK services to improve attachment in infants, conduct a systematic review assessing the evidence base for parenting attachment interventions and to develop recommendations for future research and practice on the use of these interventions.

Methods We used a national survey, focused on relevant UK services, to collect details around the interventions being used to treat attachment problems. These results informed two systematic reviews. One review searched for all RCT evidence for any parenting attachment intervention. The second review searched for all available research focused on the top ten routinely used interventions identified from the survey.

Results The survey collected 625 response from 734 services. This recorded information around which interventions were most commonly used, how they were delivered and the measures of attachment used.

For the first review, 7 studies were included from 2,516 identified records. These results were combined with a previous systematic review conducted by the research team to update two separate meta-analyses, yielding 20 studies measuring disorganised attachment and 26 studies measuring secure attachment. Overall, parenting interventions are effective in reducing disorganised attachment $(\mathrm{p}<0.001)$ and increasing secure attachment $(\mathrm{p}<0.001)$ in children.

The second review looked at all available literature for the top ten routinely used interventions identified by the survey. Searches returned 1,198 records, with a final inclusion list of 61 studies. These studies identified that the most commonly used interventions in UK services (including Individual Child Psychotherapy and Dyadic Developmental Psychotherapy) have very little or weak evidence base whereas the interventions with the strongest evidence base and highest number of RCTs (including Attachment Bio-behavioural Catch-up and Video Feedback Intervention to Promote Positive Parenting) are not widely used.

Conclusions Parenting interventions are effective in treating attachment problems. However there is a current disconnect between research and practice. The large variation in intervention research may be related to research funding opportunities or practitioner and academic preferences. The variation in practice may be related to training opportunities and costs, intervention complexity, cost and accessibility; and preferences from clinical leaders and commissioners. High quality research evaluating interventions that are used in services is needed, whilst including patient and public involvement to ensure that the research is translatable to practice. Good quality dissemination and training should also inform the public, clinicians and commissioners and shed a light on which interventions practices should use to improve attachment relationships.

Funding Statement This Project was funded by the National Institute for Health Research (NIHR) HTA programme (Project Number NIHR127810).

\section{QUALITATIVE ANALYSIS OF TELEPHONE CLINICS IN COMMUNITY PAEDIATRIC SERVICES DURING COVID-19 PANDEMIC}

Justyna Rutkowski, Ahmed Khan, Zeinab Abdelrahim, Anne Dooley. Community Paediatrics, Southern Trust, NIMDTA

\subsection{6/archdischild-2021-rcpch.430}

Background The Covid-19 pandemic has placed healthcare services under significant strain. Royal College of Paediatric \& Child Health advised use of virtual consultation where possible. ${ }^{1}{ }^{2}$ Within the published literature there is clear evidence demonstrating the many benefits of telephone consultation including telephone appointments being more convenient, more cost-effective, improved quality of care and decreased non-attendance rates. ${ }^{3}$

Telephone clinics were implemented in community paediatric services in the southern trust, Northern Ireland during the Covid-19 pandemic.

Objectives To understand service users and staff satisfaction of community paediatric phone clinics during the Covid-19 pandemic.

Methods The Quality Improvement team completed literature review on similar types of projects. A questionnaire was designed for service users to determine their satisfaction for phone clinics in community paediatrics. A separate questionnaire for (clinicians and administrative) staff was also developed to understand their experience. Feedback was obtained from randomly selected service users over the period of May to October 2020. The questionnaire was sent to service users by post with self-addressed return envelope after the phone clinic. Staff was asked to complete questionnaires for five separate phone clinics encounters during the same six-month period.

Results

Demographics

\begin{tabular}{llll}
\hline & $\begin{array}{l}1-4 \\
\text { years }\end{array}$ & $\begin{array}{l}5-10 \\
\text { years }\end{array}$ & $\begin{array}{l}11-17 \\
\text { years }\end{array}$ \\
\hline Age & 6 & 22 & 7 \\
\hline & & & Male \\
\hline Sex & Female & 26 \\
\hline
\end{tabular}

Summary of results from service user questionnaire: Total of 144 questionnaire were sent to service users and 35 returned.

\begin{tabular}{lllll}
\hline Questions & $\begin{array}{l}\text { Certainly } \\
\text { True }\end{array}$ & $\begin{array}{l}\text { Partly } \\
\text { True }\end{array}$ & $\begin{array}{l}\text { Not } \\
\text { True }\end{array}$ & N/A \\
\hline Phone clinic was booked in advance & $88.5 \%$ & $5.7 \%$ & $2.9 \%$ & $2.9 \%$ \\
Saved time by attending phone clinic & $88.5 \%$ & $11.4 \%$ & 0 & 0 \\
This type of clinic may fit into my working & $71.4 \%$ & $22.8 \%$ & 0 & $5.7 \%$ \\
life schedules & & & & \\
Phone call was at a convenient time & $97.1 \%$ & $2.9 \%$ & 0 & 0 \\
Views/worries were taken seriously & $94.2 \%$ & $5.7 \%$ & 0 & 0 \\
Given enough time to explain concerns & $97.1 \%$ & $2.9 \%$ & 0 & 0 \\
Recommend this clinic & $80 \%$ & $20 \%$ & 0 & 0 \\
\hline
\end{tabular}


Summary of results from staff questionnaire: Total of 10 staff members were requested to complete the questionnaires and 7 returned. Regarding setting/environment category of the questionnaire, staff reported $100 \%$ access to quiet area with a functioning phone as well as availability to PC with Internet connection, and access to patient chart.

\begin{tabular}{lll}
\hline Questions & Doctor & Administrative \\
\hline $\begin{array}{l}\text { Clinic Category } \\
\text { Type of clinic }\end{array}$ & Medical 19, Educational & Medical 10,0ther 5 \\
& 1 & \\
Type of patient & New 5, Review 11, Both & New 2, Review 8, Both \\
& 4 & 2 \\
Interaction Category & & N/A \\
$\begin{array}{l}\text { Quality of consultation } \\
\text { Satisfied with phone clinics }\end{array}$ & Excellent 8,Good 12 & N/A Partially 4 \\
Fulfill the goal of safe and effective & Yes 14,Partially 6 & N/A \\
care & & \\
\hline
\end{tabular}

Conclusions Telephone clinic can be a useful tool to ensure patients receive timely care via a time efficient method. This project demonstrated overall positive experience from service users. However due to small sample of returned questionnaires from service users would be a limitation of this study therefore further similar studies would be beneficial after covid-19 pandemic.

Further research would be required to establish long term impact of telephone clinics in community paediatric services.

\section{REFERENCES}

1. https://www.rcpch.ac.uk/resources/principles-conducting-virtual-consultations-children-young-people

2. https://www.rcpch.ac.uk/sites/default/files/generated-pdf/document/COVID-19-guidance-for-community-settings.pdf

3.. Miller L, Caton S, Lynch D. Telephone clinic improved quality of follow up care for chronic bowel disease. Nurs Times 2002;2002:36-8.

\section{Quality Improvement and Patient Safety}

\section{INCREASING ACCESS AND USE OF INTERPRETING SERVICES IN EVERYDAY CLINICAL PRACTICE TO IMPROVE PATIENT CARE}

'Shanghavie Loganathan, ${ }^{2}$ Esther Quinn, ${ }^{2}$ Sahana Rao. 'University of Oxford; ${ }^{2} J o h n$ Radcliffe Hospital

\subsection{6/archdischild-2021-rcpch.431}

Background Effective communication is key to providing safe, high-quality clinical care. Evidence shows that in higher income countries where English is the primary language, patients with limited English proficiency have poorer clinical outcomes and compromised patient care. As the provision of equitable, patient-centred care requires active engagement with the consultation, we posit that the use of professional interpreters within this cohort would improve clinical outcomes. Informal feedback and experience within our trust suggested that the use of interpretation services was limited and improving provision could improve patient care.

Objectives We undertook a quality improvement (QI) project to improve the use of interpretation services in paediatrics.
We set out to identify obstacles to the utilisation of services and suitable methods that would overcome them.

Methods The initial survey was conducted in 2020 and explored the use of services and barriers. A multitude of reasons for low uptake were identified, including lack of clarity over access details, time constraints and the lack of appropriate equipment. We instituted changes based on this survey, including providing information on interpretation services. This was in the format of posters, emails, and educational sessions. The access codes and contact details required were made easily available and accessible to medical staff, nursing staff and allied health professionals. Definitive guidelines for use of interpretation services and appropriate access to phones with the necessary speaker function were also provided.

Results As part of the survey 19 questionnaires were completed, with $80 \%$ being completed by doctors and $20 \%$ by nurses. $100 \%$ of respondents identified situations where they felt interpretation would have been useful. Despite this, only $63 \%$ had used the service. Furthermore, only $16 \%$ used the service as part of their routine practice.

This project was discussed and approved at the paediatric clinical governance meeting. Subsequent to our intervention in April 2020, we identified an increase in usage of interpretation services as highlighted in the table below. The project was supported by a trust-wide QI programme and after presentation to senior management and patient experience teams, we were able to focus on its incorporation into induction programmes. Finally, we were also able to promote the use of interpreters at regional paediatric meetings.

\begin{tabular}{lllllll}
\hline Month & January & February & March & April & May & June \\
\hline $\begin{array}{l}\text { Total } \\
\text { Calls }\end{array}$ & 43 & 26 & 29 & 26 & 31 & 36 \\
\hline
\end{tabular}

During the COVID pandemic, there was a shift towards remote working and virtual clinics which required adaptation of our guidelines and systems. This information was also disseminated throughout the department but a repeat survey had to be postponed due to trainee redeployment during the COVID pandemic.

Conclusions Staff identified that interpretation services were beneficial to their clinical practice and patients, but there was a perceived lack of support and resources. We addressed this by improving awareness, providing education and increasing access for all members of the multi-disciplinary team. We recognise that only continuous education and structural implementation of interpretation systems at an organisational level, can allow sustainable implementation of this model.

\section{Quality Improvement and Patient Safety}

\section{UTILISING MHEALTH IN THE COVID-19 ERA}

${ }^{1}$ Ahmed Khan, ${ }^{2}$ Anne Brennan, 'Sanjeev Kamath, 'Tanmoy Chakrabarty, 'Julie McConville, ${ }^{2}$ Vincent Browne. 'Southern Health and Social Care Trust; ${ }^{2}$ Clinical Leadership Solutions

10.1136/archdischild-2021-rcpch.432 